\title{
Low serum cholesteryl ester-docosahexaenoic acid levels in Alzheimer's disease: a case-control study
}

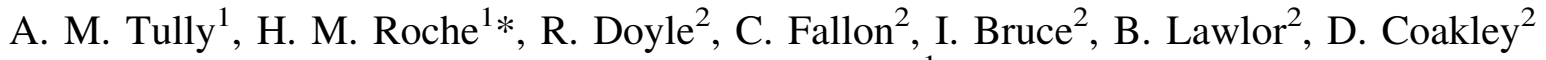 \\ and M. J. Gibney ${ }^{1}$ \\ ${ }^{1}$ Unit of Nutrition, Department of Clinical Medicine, Trinity Centre for Health Sciences and \\ ${ }^{2}$ The Mercer's Institute for Research in Ageing, St James Hospital, Dublin 8, Republic of Ireland
}

(Received 20 December 2001 - Revised 31 October 2002 -Accepted 6 November 2002)

\begin{abstract}
Low $n-3$ polyunsaturated fatty acid (PUFA) status may be associated with neuro-degenerative disorders, in particular Alzheimer's disease, which has been associated with poor dietary fish or n-3 PUFA intake, and low docosahexaenoic acid (DHA) status. The present case-control study used an established biomarker of $n$-3 PUFA intake (serum cholesteryl ester-fatty acid composition) to determine $n$-3 PUFA status in patients with Alzheimer's disease, who were free-living in the community. All cases fulfilled the National Institute of Neurological and Communicative Disorders and Stroke and Alzheimer's Disease and Related Disorders Association criteria for Alzheimer's disease. Detailed neuropsychological testing and neuroimaging established the diagnosis in all cases. The subjects (119 females and twenty-nine males) aged 76.5 (SD 6.6) years had a clinical dementia rating (CDR) of 1 (SD 0.62) and a mini mental state examination (MMSE) score of 19.5 (SD 4.8). The control subjects (thirty-six females and nine males) aged 70 (SD 6.0) years were not cognitively impaired (defined as MMSE score <24): they had a mean MMSE score of 28.9 (SD 1.1). Serum cholesteryl ester-eicosapentaenoic acid and DHA levels were significantly lower $(P<0.05$ and $P<0.001$ respectively) in all MMSE score quartiles of patients with Alzheimer's disease compared with control values. Serum cholesteryl ester-DHA levels were progressively reduced with severity of clinical dementia. DHA levels did not differ in patients with Alzheimer's disease across age quartiles: all were consistently lower than in control subjects. Step-wise multiple regression analysis showed that cholesteryl ester-DHA and total saturated fatty acid levels were the important determinants of MMSE score and CDR. It remains to be determined whether low DHA status in Alzheimer's disease is a casual factor in the pathogenesis and progression of Alzheimer's disease.
\end{abstract}

Alzheimer's disease: Docosahexaenoic acid: $n$-3 Polyunsaturated fatty acids

In developed countries, the incidence of Alzheimer's disease $(\mathrm{AD})$ is $2.8 \%$ in the age range $70-74$ years and rises to $11.1 \%$ in the age range 80-84 years (Jorm et al. 1987). It has been estimated, based on demographic projections, that between 1990 and 2010, the number of cases of $\mathrm{AD}$ in developed countries will rise by nearly $40 \%$. In recent years, there has been an increased interest in the possible involvement of nutrition in AD. Nutrients and metabolites such as folic acid, vitamin $B_{12}$, vitamin $\mathrm{B}_{6}$ and homocysteine have been the focus of attention (Nourhashémi et al. 2000). Docosahexaenoic acid (DHA) is present in large amounts in neuron membrane phospholipids, where it is required for optimal development and function of the nervous system. Recent studies suggest that $n-3$ polyunsaturated fatty acid (PUFA) consumption is beneficial in the treatment of depression (Hibbeln, 1998) and bipolar affective disorder (Stoll et al. 1999). Preliminary reports suggest that low $n-3$ PUFA status may also be associated with neuro-degenerative disorders, whereby poor dietary fish or $n-3$ PUFA intake, and low DHA status have been associated with the incidence of AD. The Rotterdam study, a prospective study of dietary fat composition and $\mathrm{AD}$ in elderly subjects, observed that high saturated fat intake and low levels of fish consumption in elderly subjects with a normal mini mental state examination (MMSE) score were risk factors for the subsequent development of Alzheimer's disease (Kalmijn et al. 1997b). In a study published in abstract form only, 1188 elderly subjects were studied prospectively for 10 years. It was observed that subjects who had a

Abbreviations: AD, Alzheimer's disease; CDR, clinical dementia rating; DHA, docosahexaenoic acid; MMSE, mini mental state examination; PUFA, polyunsaturated fatty acid.

* Corresponding author: Dr Helen M. Roche, fax +3531454 2043, email hmroche@tcd.ie 
lower initial serum phosphatidylcholine-DHA (22:6n-3) levels had a higher $(67 \%)$ risk of subsequently developing $\mathrm{AD}$, although the difference was not significant (Kyle et al. 1999). However, these results should be interpreted with caution, as a more than fivefold lower overall incidence of $\mathrm{AD}$ was observed in this study group compared with average US incidence rates (6-10\%) (Hendrie, 1998).

A limited number of intervention studies have explored the impact of increased fish or $n-3$ PUFA on the severity of existing AD. One such study supplemented sixty volunteers for 4 weeks with an $n-6$ PUFA $+n-3$ PUFA oil (ratio $4: 1$ ) with $\alpha$-linolenic acid $(18: 3 n-3)$ as the $n$-3 PUFA source. Improvement in severity of disease (mood, cooperation, appetite, sleep, ability to navigate and short-term memory) was observed (Yehuda et al. 1996). In a study of moderately severe dementia from thrombotic cerebrovascular disease, Terano et al. (1999) reported, in abstract form, an improvement in the severity of the disease when subjects were supplemented for 1 year with $0.72 \mathrm{~g} \mathrm{DHA} / \mathrm{d}$.

Thus, while there are some studies linking fish consumption and/or $n$-3 PUFA status with $\mathrm{AD}$, the literature is limited by either the crude estimates of fish intake (Kalmijn et al. $1997 b$ ) or the limited clinical details presented in abstract form (Peers, 1990; Yehuda et al. 1996; Terano et al. 1999). Therefore, the objective of the present case-control study was to use an established biomarker of $n-3$ PUFA intake (plasma cholesteryl ester-fatty acid composition) to determine $n$-3 PUFA status in patients with AD with precise clinical definition and who were free-living in the community.

\section{Methods}

\section{Study population}

Ethical approval for the study was granted by the Ethics Committee of the Federated Dublin Voluntary Hospitals in Ireland. Patients were recruited from the Mercer Institute for Research on Ageing, St James Hospital, as part of an ongoing multi-factorial study on patients with AD. All patients attending the clinic were community-based; none was institutionalised. All cases fulfilled the criteria of the National Institute of Neurological and Communicative Disorders and Stroke and Alzheimer's Disease and Related Disorders Association for probable and possible AD (McKhann et al. 1984) and the International Classification of Diseases, 10th revision (ICD-10) criteria for mixed and vascular dementia (World Health Organization, 1992). Detailed neuropsychological testing and neuroimaging was used to establish the diagnosis in all cases (Swanwick et al. 1996). The subjects were 119 females and twenty-nine males with a mean age of 76.5 (SD 6.6) (range 49-92) years and mean clinical dementia rating (CDR) (Hughes et al. 1982) of 1 (SD 0.62). The attendance at the clinic showed a marked preponderance towards women. The mean MMSE score (Folstein et al. 1975) of the subject group was 19.5 (SD 4.8) (Range 2-27). The diagnoses included probable $\mathrm{AD}$ ( $n$ 108), possible $\mathrm{AD}(n$ 16), mixed $\mathrm{AD}$ (n 13 subjects) and vascular dementia ( $n$ 11). Non-fasting serum samples were taken from AD subjects, centrifuged, divided into portions and stored at $-20^{\circ} \mathrm{C}$ until analysis for cholesteryl ester-fatty acid composition.
The elderly control subjects were recruited from local active retirement groups; they were not cognitively impaired (MMSE score <24). Each control subject underwent an assessment that included taking a medical history, brief neurological assessment, and height, weight and bloodpressure measurements. Global cognition of the healthy control was also assessed by the MMSE (Folstein et al. 1975; Reisberg et al. 1985), a screening test of dementia in older people. The control subjects were thirty-six females and nine males with a mean age of 70 (SD 6) (Range 53-81 years) and a mean MMSE score of 28.9 (SD 1.1) (range 2530). Habitual dietary supplement use was also examined in the control group. Five control subjects were habitual consumers of cod-liver oil supplements and two subjects reported occasional supplement use. Non-fasting serum samples were taken from control subjects, centrifuged, divided into portions and stored at $-20^{\circ} \mathrm{C}$ until analysis. Exclusion criteria were: (1) history of stroke; (2) hypertension; (3) MMSE score $<24$; (4) current warfarin therapy.

\section{Cholesteryl ester-fatty acid analysis}

Lipid extractions were performed using the procedure of Folch et al. (1957). Cholesteryl esters were isolated using TLC on silica 60 LKD 19 Lane TLC plates (Whatman; Clifton, NJ, USA) using a solvent system of light petroleum $\left(40-60^{\circ} \mathrm{C}\right)$-diethyl ether-formic acid $(80: 20: 2$, by vol.) (Gibney \& Bolton-Smith, 1988). Cholesteryl esters were hydrolysed using $0.5 \mathrm{M}-\mathrm{NaOH}$ in methanol and incubated at $80^{\circ} \mathrm{C}$ for $30 \mathrm{~min}$ (Glatz et al. 1989). Component fatty acids were methylated using $\mathrm{BF}_{3}$ in methanol. GLC was used to identify fatty acid methyl esters of cholesteryl esters using a Shimadzu CG-14A Series GC (Mason Technologies, Dublin, Ireland). Specific fatty acid levels were expressed as $\mathrm{g} / 100 \mathrm{~g}$ total fatty acids and fatty acid compositions of patients and controls were analysed randomly. The average storage period of the patient serum samples was 2.54 years. The long-term stability of frozen serum samples for cholesteryl ester-fatty acid compositional analysis was demonstrated by Simon et al. (1995), who showed that serum cholesteryl ester-fatty acid composition of samples frozen for 3 years was not significantly from that of freshly analysed samples.

\section{Data handling and statistical analysis}

All statistical analyses were completed with the Apple Macintosh compatible statistical package Data Desk 4.1 (Data Description Inc., New York, USA). Repeatedmeasures ANOVA was used to describe differences between groups. Step-wise multiple regression analysis was performed to determine the relative importance of age, sex and fatty-acid composition on AD status. Fatty acids were log transformed to give a normal Gaussian distribution to permit parametric statistical analysis to be performed.

\section{Results}

The age, sex and cholesteryl ester-fatty acid composition of the AD patients, compared with control values, are presented in Table 1 . The patients were divided according 
Table 1. Cholesteryl ester-fatty acid composition ( $\mathrm{g} / 100 \mathrm{~g}$ total fatty acids) in subjects with Alzheimer's disease classified as quartiles of mini mental examination score compared with control subjects $\dagger$

(Mean values and standard deviations)

Quartiles of MMSE score for Alzheimer's disease patients

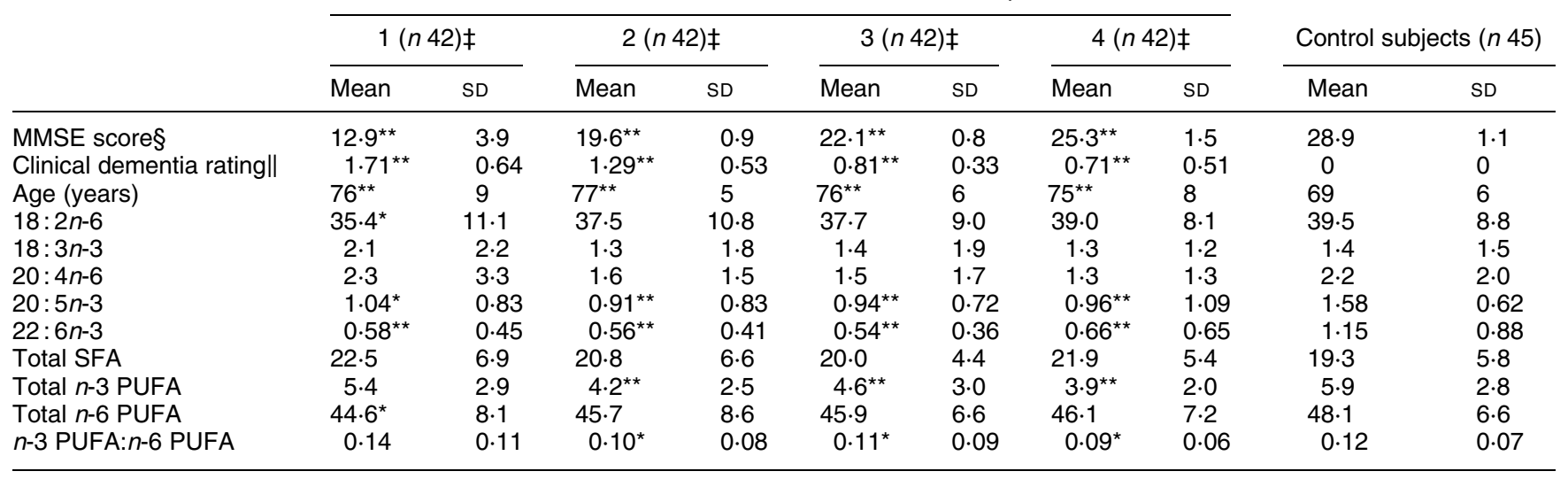

MMSE, mini mental state examination; SFA, saturated fatty acid; PUFA, polyunsaturated fatty acid.

Mean values were significantly different from those of control subjects: ${ }^{\star} P<0.05,{ }^{\star \star} P<0.001$.

$\dagger$ For details of subjects and procedures, see p. 484.

‡Female $(n) /$ male $(n)$ : first quartile 33/9; second quartile 33/9; third quartile 34/8; fourth quartile $31 / 11$; control subjects $36 / 9$.

$\S$ For details, see Folstein et al. (1995).

\|l For details, see Hughes et al. (1982).

to quartiles of MMSE score. Therefore, both the MMSE score and the CDR differed significantly across all MMSE score quartiles compared with control values $(P<0 \cdot 001)$. Subjects in all MMSE score quartiles were significantly older $(P<0 \cdot 001)$ than control subjects. There were no significant differences in the female $(n)$ :male $(n)$ ratio. Plasma cholesteryl ester levels of linoleic acid $(18: 2 n-6)$ and total $n-6$ PUFA levels were significantly lower $(P<0.05)$ in the lowest quartile of MMSE score among patients compared with control values. The remaining quartiles of MMSE score did not exhibit significantly lower levels of linoleic acid or $n$-6 PUFA compared with control subjects. Plasma cholesteryl ester-eicosapentaenoic acid (20:5n-3) and DHA (22:6n-3) levels were significantly lower $(P<0.05$ and $P<0.001$ respectively) in all MMSE score quartiles of patients with AD compared with control values. When total $n$-3 PUFA were considered (including $\alpha$-linolenic acid $(18: 3 n-3)$, the three highest MMSE score quartiles were significantly different from control values $(P<0.001)$. It was also observed that patients in the two lowest MMSE score quartiles had significantly $(P<0.05)$ higher (12.03 (SD 3.4) and 12.20 (SD 3.2) $\mathrm{g} / 100 \mathrm{~g}$ total fatty acids respectively) levels of the saturated fatty acid palmitic acid (16:0) compared with control values (10.64 (SD 2.01) g/100 g total fatty acids). Table 2 shows the level of the two long-chain $n$-3 PUFA, eicosapentaenoic acid and DHA, in plasma cholesteryl esters in the patient group, classified according to CDR, clinical diagnosis of $\mathrm{AD}$ and quartile of age. It demonstrates that in almost all cases, the patients with $\mathrm{AD}$ had significantly lower levels $(P<0.001)$ of both long-chain $n$-3 PUFA compared to control values. This was especially true for DHA. It is important to note that the levels of DHA did not differ significantly in patients with a clinical diagnosis of $\mathrm{AD}$ across age quartiles, but they were all consistently lower than control values. Step-wise multiple regression analysis was performed to determine the relative importance of age, sex and fatty acid composition (linoleic acid, arachidonic acid, eicosapentaenoic acid, DHA, saturated fatty acids, monounsaturated fatty acids, $n-6$ PUFA, $n-3$ PUFA, $n-3: n-6$ PUFA ratio) on AD status. For CDR, cholesteryl ester-DHA $(\beta-0.517, P=0.0006)$, followed by cholesteryl ester-total saturated fatty acid levels $(\beta$ $1.224, P=0.0044)$ and age $(\beta 0.021, P=0.0052)$ were important determinants of MMSE score, according to the regression equation $(r \quad 0.429, \quad P=0.0008)$. Similarly, MMSE score was also predicted cholesteryl ester-DHA $(\beta$ 4.048, $P=0.001)$ and cholesteryl ester-total saturated fatty acid levels $(\beta-7.48, P=0.034)$, but age was not a significant predictor $(\beta-0 \cdot 101, P=0 \cdot 100)$, according to the regression equation $(r 0.352, P=0.0001)$.

\section{Discussion}

The present case-control study provides evidence that patients with $\mathrm{AD}$ have low $n$-3 PUFA status. The level of DHA in the serum cholesteryl ester fraction of $\mathrm{AD}$ patients was consistently half that in the control group. The cohort of patients with $\mathrm{AD}$, who attended the memory clinic for assessment, are particularly interesting because they were diagnosed with precise clinical markers and were free-living in the community. The patients with $\mathrm{AD}$ were well nourished and generally physically healthy, apart from common medical complaints and medications associated with ageing. A recent paper has shown similar prevalence of medical conditions (e.g. hypertension, atrial fibrillation, cerebro- or cardiovascular disease) and general use of medications in both community-dwelling AD subjects and control subjects in this population (Cunningham et al. 2001). While other diseases could be associated with lower levels of $n$-3 PUFA, clinical notes recorded that both groups were essentially healthy, apart from the 
Table 2. Serum cholesteryl ester-eicosapentaenoic acid $(20: 5 n-3)$ and dososahexaenoic acid $(22: 6 n-3)$ levels $(\mathrm{g} / 100 \mathrm{~g}$ total fatty acids) in Alzheimer's disease patients classified according to clinical dementia rating, clinical diagnosis and age quartiles $\dagger$

(Mean values and standard deviations)

\begin{tabular}{|c|c|c|c|c|c|c|c|}
\hline & \multirow[b]{2}{*}{$n$} & \multicolumn{2}{|c|}{ Age } & \multicolumn{2}{|c|}{ EPA $(20: 5 n-3)$} & \multicolumn{2}{|c|}{ DHA $(22: 6 n-3)$} \\
\hline & & Mean & SD & Mean & SD & Mean & SD \\
\hline $\begin{array}{l}\text { Control subjects } \\
\text { Clinical dementia rating:t }\end{array}$ & 45 & & & 1.58 & 0.62 & $1 \cdot 15$ & 0.88 \\
\hline Mild & 53 & & & $0.80^{\star \star *}$ & 0.71 & $0.58^{\star \star *}$ & 0.47 \\
\hline Moderate & 64 & & & $1 \cdot 05^{\star \star \star}$ & 0.95 & $0.51^{\star \star \star}$ & 0.34 \\
\hline Moderate or severe & 41 & & & 1.09 & 0.98 & $0.49^{\star \star \star}$ & 0.35 \\
\hline \multicolumn{8}{|c|}{ Clinical diagnosis of Alzheimer's disease:§ } \\
\hline Probable & 108 & & & $0.98^{\star \star *}$ & 0.87 & $0.56^{\star \star \star}$ & 0.41 \\
\hline Possible & 16 & & & $0.95^{\star \star \star}$ & 0.87 & $0.54^{\star \star \star}$ & 0.36 \\
\hline Mixed & 13 & & & 1.49 & $1 \cdot 16$ & $0 \cdot 67^{\star \star \star}$ & 0.66 \\
\hline Vascular & 11 & & & $0.62^{\star}$ & 0.44 & $0.49^{* * *}$ & 0.47 \\
\hline \multicolumn{8}{|c|}{ Age quartile of probable Alzheimer's disease patients: } \\
\hline 1 & 27 & 68 & 6 & $1 \cdot 19$ & 1.07 & 0.52 & 0.32 \\
\hline 2 & 27 & 74 & 1 & 0.89 & 0.67 & 0.67 & 0.46 \\
\hline 3 & 27 & 78 & 1 & 0.89 & 0.72 & 0.49 & 0.31 \\
\hline 4 & 27 & 84 & 3 & 0.97 & 0.98 & 0.55 & 0.50 \\
\hline
\end{tabular}

EPA, eicosapentaenoic acid; DHA, docosahexaenoic acid.

Mean values were significantly different from those of control subjects: ${ }^{\star} P<0.05,{ }^{\star \star *} P<0.001$.

† For details of subjects and procedures, see p. 484.

$\ddagger$ For details, see Folstein et al. (1995).

$\S$ For details of diagnosis and classification, see p. 484 and McKhann et al. (1984) and the World Health Organization (1992).

presence of different stages of $\mathrm{AD}$, as defined using strict diagnostic criteria. Nevertheless it is possible, albeit unlikely, that another undiagnosed underlying condition that could alter $n$-3 PUFA status may have accounted for the differences between groups.

DHA is the most abundant $n-3$ PUFA in vivo. It is present in the retina and a principal component of neuronal membrane phospholipids, where it is required for optimum development and function of the nervous system. The present study used plasma cholesteryl ester-fatty acid composition as a biomarker of DHA status may be related to AD. Cholesteryl ester-fatty acid composition is a wellestablished biomarker of fatty acid status in vivo and a marker of dietary fat intake (Nikkari, 1986; Simon et al. 1995). It is not subject to inherent methodological errors associated with available dietary assessment techniques to cognitive impairment and incomplete food composition databases. Our present results agree with the results of the Rotterdam study, a large prospective populationbased study, which showed that high saturated fat and low $n$-3 PUFA intake were associated with an increased incidence of AD (Kalmijn et al. 1997b). They also agree with results reported in an abstract that reported a 10-year follow-up study of more than 1000 elderly US subjects that demonstrated that low levels of serum phosphatidylcholine-DHA was a significant risk factor for low MMSE score and the development of $\mathrm{AD}$ (Kyle et al. 1999). Furthermore, Prasad et al. (1998) demonstrated that DHA concentrations were significantly lower in the phosphatidylethanolamine and phosphatidylinositol fractions of brain membrane phospholipids in $\mathrm{AD}$ patients compared with control subjects: In vitro studies show that DHA plays an important role in the survival of neuron cells, and it has been postulated that it may be modulator phosphatidylserine biosynthesis, which in turn can effect neuronal signalling (Kim \& Edsall, 1999). Hence, the present study adds to the growing evidence that poor DHA status is either a risk factor or marker of AD. A possible limitation of our present study is that cholesteryl ester-fatty acid composition was completed in frozen serum samples because long-chain fatty acids are susceptible to oxidative damage. However, the long-term stability of frozen serum samples of cholesteryl esterfatty acid compositional analysis was demonstrated by Simon et al. (1995), who showed little oxidative damage and no significant alteration in the serum cholesteryl ester-fatty acid composition of samples frozen for 3 years.

A potential criticism of the present study is that the control subjects were younger than the patient group, since cognitive performance decreases with increasing age (Kalmijn et al. 1997a). However, even when the patients with $\mathrm{AD}$ were divided according to age quartiles, plasma cholesteryl ester-DHA levels were still consistently less than half that of the control subjects, irrespective of age. In addition, a subgroup of forty-one age- and sex-matched patients and control subjects were compared and this analysis showed that the patients had significantly lower eicosapentaenoic acid and DHA concentrations than control subjects $(P<0.001)$ (Table 3). Furthermore, age was included as a variable in the step-wise multiple regression analysis and it was only a significant predictor of CDR, after cholesteryl esterDHA and SFA levels. Another study has demonstrated that the decrease in brain phosphatidylethanolamine-DHA levels in $\mathrm{AD}$ patients was not due to ageing, and ageing was shown to have no influence on the fatty acid composition of the brain (Soderberg et al. 1991). 
Table 3. Characteristics and plasma cholesteryl ester composition ( $\mathrm{g} / 100 \mathrm{~g}$ total fatty acid) of age- and, sexmatched patients with Alzheimer's disease and healthy elderly controls $\uparrow$

(Mean values and standard deviations)

\begin{tabular}{|c|c|c|c|c|}
\hline & \multicolumn{2}{|c|}{ Patients ( $n$ 41) $\ddagger$} & \multicolumn{2}{|c|}{$\begin{array}{l}\text { Control Subjects } \\
\qquad(n 41) \ddagger\end{array}$} \\
\hline & Mean & SD & Mean & SD \\
\hline CDR§ & $1.06^{\star * *}$ & 0.66 & 0.0 & 0.0 \\
\hline MMSE score\|l & $19 \cdot 78^{\star \star \star}$ & 4.93 & 28.90 & 1.14 \\
\hline Age (years) & $70 \cdot 80$ & 4.63 & 69.83 & $5 \cdot 04$ \\
\hline $16: 0$ & $11 \cdot 74$ & 3.20 & 10.54 & 2.00 \\
\hline $16: 1$ & 4.44 & 1.73 & 4.39 & 1.45 \\
\hline $18: 0$ & 3.82 & 2.55 & 4.66 & $4 \cdot 71$ \\
\hline $18: 1$ & $18 \cdot 91$ & $5 \cdot 62$ & 18.94 & 4.69 \\
\hline $18: 2 n-6$ & 38.95 & $8 \cdot 81$ & $40 \cdot 04$ & $8 \cdot 76$ \\
\hline $18: 3 n-3$ & 1.29 & 1.79 & 1.44 & 1.53 \\
\hline $18: 4 n-3$ & 1.74 & 1.65 & 1.74 & 1.65 \\
\hline $20: 4 n-6$ & 1.55 & 1.75 & $2 \cdot 22$ & $2 \cdot 01$ \\
\hline $20: 5 n-3$ & $1.06^{\star * *}$ & 1.04 & 1.55 & 0.63 \\
\hline $22: 6 n-3$ & $0.44^{\star \star \star}$ & 0.30 & 1.07 & 0.83 \\
\hline
\end{tabular}

CDR, clinical dementia rating; MMSE, mini mental state examination.

Mean values were significantly different from those of control subjects: ${ }^{* \star \star} P<0.001$

†For details of subjects and procedures, see p. 484

$\ddagger$ Female $(n) /$ male $(n)$ : patients 32/9; control subjects $32 / 9$.

$\S$ For details, see Folstein et al. (1995).

\| For details, see Hughes et al. (1982).

It was beyond the scope of the present study to evaluate how low DHA and/or $n$-3 PUFA status is associated with an increased incidence of AD. Nevertheless, there are several plausible hypotheses to support the apparent inverse association. First, $n-3$ PUFA and/or fish intake may protect against dementia by reducing cardiovascular disease risk. Epidemiological, case-control, secondary prevention and intervention studies show a strong inverse association between $n$-3 PUFA and cardiovascular disease (Bang et al. 1971; Kromhout et al. 1985; Burr et al. 1989; Singh et al. 1997; Albert et al. 1998). In addition, cardiovascular disease increases the risk of dementia and its major subtypes AD and vascular dementia (Hofman et al. 1997). Second, inflammatory processes are also involved in the pathogenesis of AD (Kalmijn et al. 1997a). Increased concentrations of acute-phase proteins and pro-inflammatory cytokines are characteristic of patients with AD. $n-3$ PUFA reduce the synthesis of pro-inflammatory cytokines (Billiar et al. 1988; Caughey et al. 1996; Block et al. 1997), and therefore could attenuate the pro-inflammatory components of the disease. In human subjects, most supplementation studies showing an immunomodulatory effect of $n-3$ PUFA have used high doses, usually $>2 \mathrm{~g} / \mathrm{d}$. It has been demonstrated that even low doses of fish oil $(0.6 \mathrm{~g} / \mathrm{d})$ in the short-term (6 weeks) are sufficient to affect the immune response beneficially by decreasing lymphocyte proliferation in elderly subjects (age $>70$ years) (Bechoua et al. 1999). Third, since dietary $n-3$ fatty acids are essential for normal nervous system development in man, adequate DHA status may protect against AD. $n-3$ PUFA can be incorporated in the brains of animals after a period of brain development (Neuringer \& Connor, 1986), and therefore could be important in neuronal regeneration (Compston, 1994).
The observed low DHA status in our present study may be either a risk factor or simply a marker of AD. Low DHA status associated with AD could be due to: reduced dietary intake of $n$-3 PUFA; reduced long-chain $n-3$ PUFA elongation and/or desaturation enzyme activity; reduced synthesis and/or increased utilisation of EPA and DHA as a result of the disease process. Dietary sources of DHA are oily fish and $n-3$ PUFA supplements, such as cod-liver oil. However, it cannot be concluded that the absence of fish in the diet predisposes to AD. Broe et al. (1990) found no association between the absence of fish in the diet and $\mathrm{AD}$ in a large group of elderly volunteers in a case-control study. Nevertheless, it has been shown that AD patients, whose diet was originally high in $n-6$ PUFA and almost devoid of $n$-3 PUFA, show improvement in severity and rate of decline of the condition when supplemented with oily fish two times per week (Peers, 1990; Yehuda et al. 1996; Terano et al. 1999).

Membrane structure and cellular functions are influenced by fatty-acid composition, which in turn is regulated by a synthesis-degradation system that involves $\Delta 5$ - and $\Delta 6$ desaturase activities and peroxisomal $\beta$-oxidation (Voss et al. 1991). DHA may be synthesized from its precursor $\alpha$ - linolenic acid, through elongation and desaturation of $\alpha$-linolenic acid into eicosapentaenoic acid, then elongation and peroxisomal $\beta$-oxidation into DHA (Périchon et al. 1998). This process is quite inefficient. It has been shown that $15.4 \mathrm{~g} \alpha$-linolenic acid/d is required to cause an equivalent increase in platelet eicosapentaenoic acid levels as $70 \mathrm{mg}$ eicosapentaenoic acid/d (Li et al. 1999). There is little information in relation to the conversion of $\alpha$-linolenic acid into DHA, but it can be assumed that this is even less efficient. It has been proposed that the metabolic capacity of fatty acid synthesis and/or degradation declines with age and age-related diseases, which could contribute to the reduction in DHA in $\mathrm{AD}$ disease (Périchon et al. 1998; Babin et al. 1999). Hence it may be that $\Delta 5$ - and $\Delta 6$ - desaturase activities and/or peroxisomal $\beta$-oxidation are adversely affected in $\mathrm{AD}$ and reduce DHA synthesis in vivo. Nakada et al. (1990) found elevated levels of $\alpha$-linolenic acid and reduced levels of DHA in brain-membrane phospholipids taken from autopsied AD patients compared with age-matched controls. This alteration in ALA and DHA in AD disease indicated a possible abnormality in $\Delta 6$ - desaturase activity or a peroxisomal defect and it was proposed that the resultant membrane abnormalities play a key role in the pathogenesis of AD. In our present study, AD patients had a higher $\alpha$-linolenic acid:DHA ratio compared with control subjects, which would again imply an accumulation of $\alpha$-linolenic relative to DHA due to a defect in retroconversion by peroxisomal $\beta$-oxidation and/ or $\Delta 5$ - or $\Delta 6$-desaturase activities. Indeed, the patients with the lowest MMSE scores who were most severely affected by the disease showed an accumulation of $\alpha$-linolenic compared with control subjects, but the more mildly affected patients did not.

To conclude, our present study shows that free-living AD patients have lower DHA status compared with healthy control subjects. It remains to be determined whether and/ or how low DHA status plays an aetiological role in the pathogenesis and/or progression of AD Low DHA status 
may simply a marker of the disease process. Nevertheless, in light of the cardio-protective and anti-inflammatory capabilities of $n$-3 PUFA, it is important that the true nature of the effect of DHA on AD is investigated.

\section{References}

Albert CM, Hennekens CH, O’Donnell CJ, Ajani UA, Carey VJ, Willett WC, Ruskin JN \& Manson JE (1998) Fish consumption and risk of sudden cardiac death. Journal of the American Medical Association 279, 23-28.

Babin F, Abderrazik M, Favier F, Cristol JP, Léger CL, Papoz L \& Descomps B (1999) Differences between polyunsaturated fatty acid status of non-institutionalized elderly women and younger controls: a bioconversion defect can be suspected. European Journal of Clinical Nutrition 53, 591-596.

Bang HO, Dyerberg J \& Nielsen AB (1971) Plasma lipid and lipoprotein pattern in Greenlandic west-coast Eskimos. Lancet 1, 1143-1145.

Bechoua S, Dubois M, Nemoz G, Chapuy P, Vericel E, Lagarde M \& Prigent AF (1999) Very low dietary intake of $n$-3 fatty acids affects the immune function of healthy elderly people. Lipids 34, 143S.

Billiar TR, Bankey PE, Svingen BA, Curran RD, West MA, Holman RT, Simmons RL \& Cerra FB (1988) Fatty acid intake and Kupffer cell function: fish oil alters eicosanoid and monokine production to endotoxin stimulation. Surgery 104, 343-349.

Blok WL, Deslypere JP, Demacker PN, van der Ven-Jongekrijg J, Hectors MP, van der Meer JW \& Katan MB (1997) Pro- and anti-inflammatory cytokines in healthy volunteers fed various doses of fish oil for 1 year. European Journal of Clinical Investigation 27, 1003-1008.

Broe GA, Henderson AS, Creasey H, McCusker E, Korten AE, Jorm AF, Longley W \& Anthony JC (1990) A case-control study of Alzheimer's disease in Australia. Neurology 40, $1698-1707$

Burr ML, Fehily AM, Gilbert JF, Rodgers S, Holliday RM, Sweetman PM, Elwood PC \& Deadman NM (1989) Effects of changes in fat, fish and fibre intakes on death and myocardial reinfarction: diet and reinfarction trial (DART). Lancet $\mathbf{2}$, 757-761.

Caughey GE, Mantzioris E, Gibson RA, Cleland LG \& James MJ (1996) The effect on human necrosis factor $\alpha$ and interleukin $1 \beta$ production of diets enriched in $n-3$ fatty acids from vegetable oil or fish oil. American Journal of Clinical Nutrition 63, 116-122.

Compston A (1994) Brain repair: an overview. Journal of Neurology 241, 1S-4S.

Cunningham CJ, Sinnott M, Denihan A, Rowan M, Walsh JB, O'Moore R, Coakley D, Coen RF, Lawlor BA \& O'Neill DD (2001) Endogenous sex hormone levels in postmenopausal women with Alzheimer's disease. Journal of Clinical Endocrinology and Metabolism 86, 1099-1103.

Folch J, Lees M \& Stanley GHS (1957) A simple method for the isolation and purification of total lipides from animal tissues. Journal of Biological Chemistry 226, 497-509.

Folstein MF, Folstein SE \& McHugh PR (1975) Mini-Mental State: a practical method for grading the cognitive state of patients for the clinician. Journal of Psychiatric Research 12, 189-198.

Gibney MJ \& Bolton-Smith C (1988) The effect of a dietary supplement of $n-3$ polyunsaturated fat on platelet lipid composition, platelet function and platelet plasma membrane fluidity in healthy volunteers. British Journal of Nutrition $\mathbf{6 0}$, $5-12$.

Glatz JF, Soffers AE \& Katan MB (1989) Fatty acid composition of serum cholesteryl esters and erythrocyte membranes as indicators of linoleic acid intake in man. American Journal of Clinical Nutrition 49, 269-276.

Hendrie HC (1998) Epidemiology of dementia and Alzheimer's disease. American Journal of Geriatric Psychiatry 6, 3S-18S.

Hibbeln JR (1998) Fish consumption and major depression. Lancet 351, 1213.

Hofman A, Ott A, Breteler MM, Bots ML, Slooter AJ, van Harskamp $\mathrm{F}$, van Duijn $\mathrm{CN}$, Van Broeckhoven $\mathrm{C}$ \& Grobbee DE (1997) Atherosclerosis, apolipoprotein E and the prevalence of dementia and Alzheimer's disease in the Rotterdam study. Lancet 349, 151-154.

Hughes CP, Berg L, Danziger WL, Coben LA \& Martin RL (1982) A new clinical scale for the staging of dementia. British Journal of Psychiatry 140, 566-572.

Jorm AF, Korten AE \& Henderson AS (1987) The prevalence of dementia: a quantitative integration of the literature. Acta Psychiatrica Scandinavica 76, 465-479.

Kalmijn S, Feskens EJM, Launer LJ \& Kromhout D (1997a) Polyunsaturated fatty acids, antioxidants and cognitive function in very old men. American Journal of Epidemiology 145, $33-41$.

Kalmijn S, Launer LJ, Ott A, Witteman JCM, Hofman A \& Breteler MMB (1997b) Dietary fat intake and the risk of incident dementia in the Rotterdam study. Annals of Neurology 42, 776-782.

Kim HY \& Edsall L (1999) The role of docosahexaenoic acid (22:6n-3) in neuronal signalling. Lipids 34, 249S.

Kromhout D, Bosschieter EB \& de Lezenne Coulander C (1985) The inverse relation between fish consumption and 20-year mortality from coronary heart disease. New England Journal of Medicine 312, 1205-1209.

Kyle DJ, Schaefer E, Patton G \& Beiser A (1999) Low serum docosahexaenoic acid is a significant risk factor for Alzheimer's dementia. Lipids 34, 245S.

Li D, Mann NJ \& Sinclair AJ (1999) Comparison of $n$-3 polyunsaturated fatty acids from vegetable oils, meat and fish in raising platelet eicosapentaenoic acid levels in humans. Lipids 34, 309S.

McKhann G, Drachman D, Folstein M, Katzman R, Price D \& Stadlan EM (1984) Clinical diagnosis of Alzheimer's disease: report of the NINCDS-ADRDA Work Group under the auspices of Department of Health and Human Services and Human Services Task Force on Alzheimer's Disease. Neurology 34, 939-945.

Nakada T, Kwee IL \& Ellis WG (1990) Membrane fatty acid composition shows delta-6-desaturase abnormalities in Alzheimer's disease. Neuroreport 1, 153-155.

Neuringer M \& Connor WE (1986) n-3 fatty acids in the brain and retina: evidence for their essentiality. Nutrition Reviews 44, 285-294.

Nikkari T (1986) Serum fatty acids and coronary heart diesease in Finnish populations. Progress in Lipid Research 25, 437-450.

Nourhasémi F, Gillette-Guyonnet S, Andrieu S, Ghisolfi A, Ousset PJ, Grandjean H, Grand A, Pous J, Vellas B \& Albarede JL (2000) Alzheimer disease: protective factors. American Journal of Clinical Nutrition 71, 643S-649S.

Peers RJ (1990) Alzheimer's disease and omega-3 fatty acids: hypothesis. Medical Journal of Australia 153, 563-564.

Périchon R, Bourre JM, Kelly JF \& Roth GS (1998) The role of peroxisomes in aging. Cellular and Molecular Life Sciences $\mathbf{5 4}$, 641-652.

Prasad MR, Lovell MA, Yatin M, Dhillon H \& Markesbery WR (1998) Regional membrane phospholipid alterations in Alzheimer's disease. Neurochemical Research 23, 81-88. 
Reisberg B, Ferris SH, Anand R, deLeon MJ, Scheck MJ \& Crook T (1985) Clinical assessment of cognitive decline in normal ageing and primary degenerative dementia: concordant ordinal measures. In Psychiatry 5, pp. 333-338 [P Pinchot, R Berner, and $\mathrm{K}$ Thau, editors]. New York: Plenum Press.

Simon JA, Hodgkins ML, Browner WS, Neuhaus JM, Bernert JT Jr \& Hulley SB (1995) Serum fatty acids and the risk of coronary heart disease. American Journal of Epidemiology 142, 469-476.

Singh RB, Niaz MA, Sharma JP, Kumar R, Rastogi V \& Moshiri M (1997) Randomized, double-blind, placebo-controlled trial of fish oil and mustard oil in patients with suspected acute myocardial infarction: the Indian experiment of infarct survival -4 . Cardiovascular Drugs and Therapy 11, 485-491.

Soderberg M, Edlund C, Kristensson K \& Dallner G (1991) Fatty acid composition of brain phospholipids in aging and in Alzheimer's disease. Lipids 26, 421-425.

Stoll AL, Severus E, Freeman MP, Rueter S, Zboyan HA, Diamond E, Gress KK \& Marangell LB (1999) Omega 3 fatty acids in bipolar disorder: a preliminary double-blind, placebo-controlled trial. Archives of General Psychiatry 56, 413-416.
Swanwick GJ, Coen RF, O’Mahony D, Tully M, Bruce I, Buggy F, Lawlor BA, Walsh JB \& Coakley D (1996) A memory clinic for the assessment of mild dementia. Irish Medical Journal 89 , $104-105$.

Terano T, Fujishiro S, Ban T, Yamamoto K, Tanaka T, Noguchi Y, Tamura Y, Yazawa K \& Hirayama T (1999) Docosahexaenoic acid supplementation improves the moderately severe dementia from thrombotic cerebrovascular diseases. Lipids 34, 345S-346S.

Voss A, Reinhart M, Sankarappa S \& Sprecher H (1991) The metabolism of 7,10,13,16,19-docosapentaenoic acid to $4,7,10,13,16,19$-docosahexaenoic acid in rat liver is independent of a 4-desaturase. Journal of Biological Chemistry 266, 19995-20000.

World Health Organization (1992) ICD-10 Classification of Mental and Behavioural Disorders. Clinical Disorders and Diagnostic Guidelines. Geneva: WHO.

Yehuda S, Rabinovitz S, Carasso RL \& Mostofsky DI (1996) Essential fatty acids preparation (SR-3) improves Alzheimer's patients quality of life. International Journal of Neuroscience 87, $141-149$ 